\title{
Treatment of psychotic symptoms in bipolar disorder with aripiprazole monotherapy: a meta-analysis
}

\author{
Konstantinos N Fountoulakis ${ }^{1 *}$, Xenia Gonda ${ }^{2}$, Eduard Vieta ${ }^{3}$, Frank Schmidt ${ }^{4}$ \\ From $1^{\text {st }}$ International Congress on Neurobiology and Clinical Psychopharmacology and European \\ Psychiatric Association Conference on Treatment Guidance \\ Thessaloniki, Greece. 19-22 November 2009
}

\section{Background}

The current article is a systematic registration and meta-analysis of the available clinical trials concerning the usefulness of aripiprazole in the treatment of the psychotic symptoms in bipolar disorder.

\section{Materials and methods}

A systematic MEDLINE and repositories search concerning clinical trials for aripiprazole in bipolar disorder.

\section{Results}

The meta-analysis of 4 RCTs on acute mania suggests that the effect size of aripiprazole vs. placebo was equal to 0.14 but a more reliable and accurate estimation is 0.18 for the total PANSS score. The effect was higher for the PANSS positive subscale (0.28), PANSS hostility subscale (0.24) and PANSS cognitive subscale (0.20), and lower for the PANSS negative (0.12). No data on the depressive phase of bipolar illness exist, while there are some data in favour of aripiprazole concerning the maintenance phase, where at week 26 all except the total PANSS score showed a significant superiority of aripiprazole over placebo $(\mathrm{d}=0.28$ for positive, $\mathrm{d}=0.38$ for the cognitive and $d=0.71$ for the hostility subscales) and at week 100 the results were similar $(\mathrm{d}=0.42,0.63$ and 0.48 respectively).

\section{Conclusions}

The data analysed for the current study support the usefulness of aripiprazole against psychotic symptoms during the acute manic and maintenance phases of bipolar illness.

\footnotetext{
13rd Department of Psychiatry, Aristotle University of Thessaloniki, Greece
}

\section{Author details}

'3rd Department of Psychiatry, Aristotle University of Thessaloniki, Greece. ${ }^{2}$ Department of Pharmacology and Pharmacotherapy and Department of Psychiatry Kutvolgyi Klinikai Tömb, Semmelweis University, Budapest, Hungary. ${ }^{3}$ Bipolar Disorders Program, Hospital Clinic, University of Barcelona, IDIBAPS, CIBERSAM, Barcelona, Spain. ${ }^{4}$ Fethke Professor, Tippie College of Business, University of lowa, USA.

Published: 22 April 2010

\section{doi:10.1186/1744-859X-9-S1-S225}

Cite this article as: Fountoulakis et al:: Treatment of psychotic symptoms in bipolar disorder with aripiprazole monotherapy: a meta-analysis. Annals of General Psychiatry 2010 9(Suppl 1):S225.
Submit your next manuscript to BioMed Central and take full advantage of:

- Convenient online submission

- Thorough peer review

- No space constraints or color figure charges

- Immediate publication on acceptance

- Inclusion in PubMed, CAS, Scopus and Google Scholar

- Research which is freely available for redistribution
C Biomed Central 